\title{
REVIEW
}

\section{Fixed Orthodontic Retainers: A Review}

\author{
Yasemin Kartal' 1 , Burçak Kaya²
}

'Department of Orthodontics, Private Practice, Antalya, Turkey

2Department of Orthodontics, Başkent University School of Dentistry, Ankara, Turkey

Cite this article as: Kartal Y, Kaya B. Fixed Orthodontic Retainers: A Review. Turk J Orthod 2019; 32(2): 110-4

\begin{abstract}
Orthodontic retention is defined as maintaining teeth in optimal aesthetic and functional position after treatment. Despite the necessity of retention phase and the factors influencing the stability of the teeth after orthodontic treatment was discussed by the orthodontist for a long time, it is accepted that a retention phase is essential for stability of orthodontic treatment results nowadays. Therefore, the application of a suitable retention method is important both for prevention of relapse after orthodontic treatment and for increasing patient satisfaction. Removable appliances had been used for many years for retention purposes. Later, fixed retainers were introduced to prevent relapse as having a number of advantages, such as better aesthetics, no need for patient cooperation, effectiveness, and suitability for lifelong retention. However, their need for precise bonding technique, fragility, and tendency to cause periodontal problems by weakening oral hygiene are some of their disadvantages.
\end{abstract}

Keywords: Orthodontic retention, tooth stability, relapse, fixed retainer, lifelong retention

\section{INTRODUCTION}

Orthodontic retention is defined as maintaining teeth in optimal aesthetic and functional position after treatment (1). Retention is a treatment phase in which clinicians have not come to a consensus and rather shapes through years as the clinician gains experience (2). The necessity of retention phase has even been a debate among orthodontists for years (3). In the $19^{\text {th }}$ century, the most important factor for stability of the teeth after orthodontic treatment was believed to be occlusion. Approaching the $20^{\text {th }}$ century, Lundstrom (4) claimed that the most important factor for stability is apical base, whereas McCauley (5) emphasized the importance of canine and molar relationship. In 1944, Tweed (6) reported that incisor inclination plays a role, and that upright incisors help in maintaining better stability during retention. Nowadays, there is a strong acceptance that a retention phase is crucial for stability of treatment results. Furthermore, lifelong retention is advised in some cases (7).

Removable appliances have been used for many years for retention purposes. In the 1970s, fixed retainers were introduced to prevent relapse in the lower incisor area (8). These retainers that are bonded to the lingual faces of the teeth are increasingly preferred by orthodontists for being both aesthetic and easy to wear by patients for long-term use $(9,10) 146$ boys. In a study published in 2002, it was reported that one-third of orthodontists preferred fixed lingual retainer in the mandible, whereas $5 \%$ preferred fixed retainers in the maxilla (11). In another study published in 2011 , it was reported that fixed retainers are preferred by $42 \%$ of orthodontists in the mandible and $11 \%$ of orthodontists in the maxilla (12).

\section{Clinical and Research Consequences}

Fixed retainers are most commonly used in the orthodontic retention phase as they have a number of advantages, such as better aesthetics, no need for patient cooperation, effectiveness, and suitability for lifelong retention (13). However, their need for precise bonding technique, fragility, and tendency to cause periodon-

Address for Correspondence: Burçak Kaya, Department of Orthodontics, Başkent University School of Dentistry Ankara, Turkey

E-mail: burcak_kaya@hotmail.com

cCopyright 2019 by Turkish Orthodontic Society - Available online at turkjorthod.org
Received: October 18, 2018 Accepted: December 25, 2018 
tal problems by weakening oral hygiene are some of their disadvantages.

In 1965, Newman (14) presented the direct bonding technique of orthodontic attachments. Later, in 1973, Kneirim (15) introduced the use of fixed retainers for orthodontic retention purposes for the first time. The wires that are used in the manufacturing of fixed retainers are categorized into generations since they have been introduced (16). These are the following:

- $\quad 1^{\text {st }}$ generation: These are $0.025-0.036$ inch blue elgiloy or stainless steel round wires. These are bonded only to lingual surfaces of canines, and loops are bended at each end to increase retention.

- $\quad 2^{\text {nd }}$ generation: These are 0.032 inch triple-stranded wires and can be bonded to lingual surfaces of all anterior teeth. These multi-stranded wires substituted plain wires as they have higher elasticity that allows physiological movement of the teeth (17).

- $\quad 3^{\text {rd }}$ generation: These are 0.032 inch stainless steel or 0.030 inch gold-coated plain wires. Their ends are sandblasted with aluminum oxide to increase mechanic retention. They are bonded to canines only (18).

- $\quad 4^{\text {th }}$ generation: These are 0.0215 inch 5 -stranded wires that can be bonded to all anterior teeth.

- $\quad 5^{\text {th }}$ generation: These are 0.032 inch, blue elgiloy plain wires that are sandblasted at the ends and bonded to canines only.

At the beginning, plain round or rectangular orthodontic wires were used as fixed retainers (1). In 1977, Zachrisson (19) presented the advantages of using multi-stranded wires as bonded retainers. Then, in 1982, Artun and Zachrisson (20) introduced the technique of bonding multi-stranded wires to canines only. Later, Zachrisson (21) applied triple-stranded wires to all anterior teeth in his studies. However, in his paper where he discussed his experience with fixed retainers for 20 years, he reported that 0.0215 inch 5 -stranded wires serve better results based on failure rates observed in follow-up sessions (21) (Figure 1).

In the last 10 years, multi-stranded wires became more popular for bonded fixed retainers (1). Meanwhile, resin fiberglass bands were introduced as an alternative $(22,23)$. However, although they were more aesthetic and smaller in size, their higher long-term failure rates and inability to allow physiological tooth movements reduced their popularity as a choice for bonded fixed retainers (Figure 2).

In recent years, bonded retainers can be manufactured using CAD-CAM systems. The studies in this area are limited as this is a very new technology. The techniques and types of wires used for manufacturing bonded retainers using CAD-CAM technology vary for each firm. In one of the techniques used, the retainers are produced by bending of prefabricated wires by the handle of a machine. The SureSmile retainer (OraMetrix, Richardson, TX, USA) that is produced by this technique uses copper-nickel-titanium wires (24). Another technique is producing bond- ed retainers by carving out of a block of wire. The Memotain retainer (CA-Digital, Mettmann, Germany) that is produced by this technique is manufactured from nickel-titanium wires of $0.014 \times 0.014$ inch thickness (25) (Figure 3).

Fixed bonded retainers are generally used in two ways. First, thicker 0.032 inch wires are bonded to canines only. Although stainless steel wires are mostly preferred in this technique, Liou et al. (26) reported successful results for nickel-titanium wires as well. Second, retainers made of 0.0175-0.0215 inch wires are bonded to each tooth usually from canine to canine. The indications for these two techniques differ from one another (1).

The indications for bonding fixed retainers to only canines were defined by Lee (27) as follows:
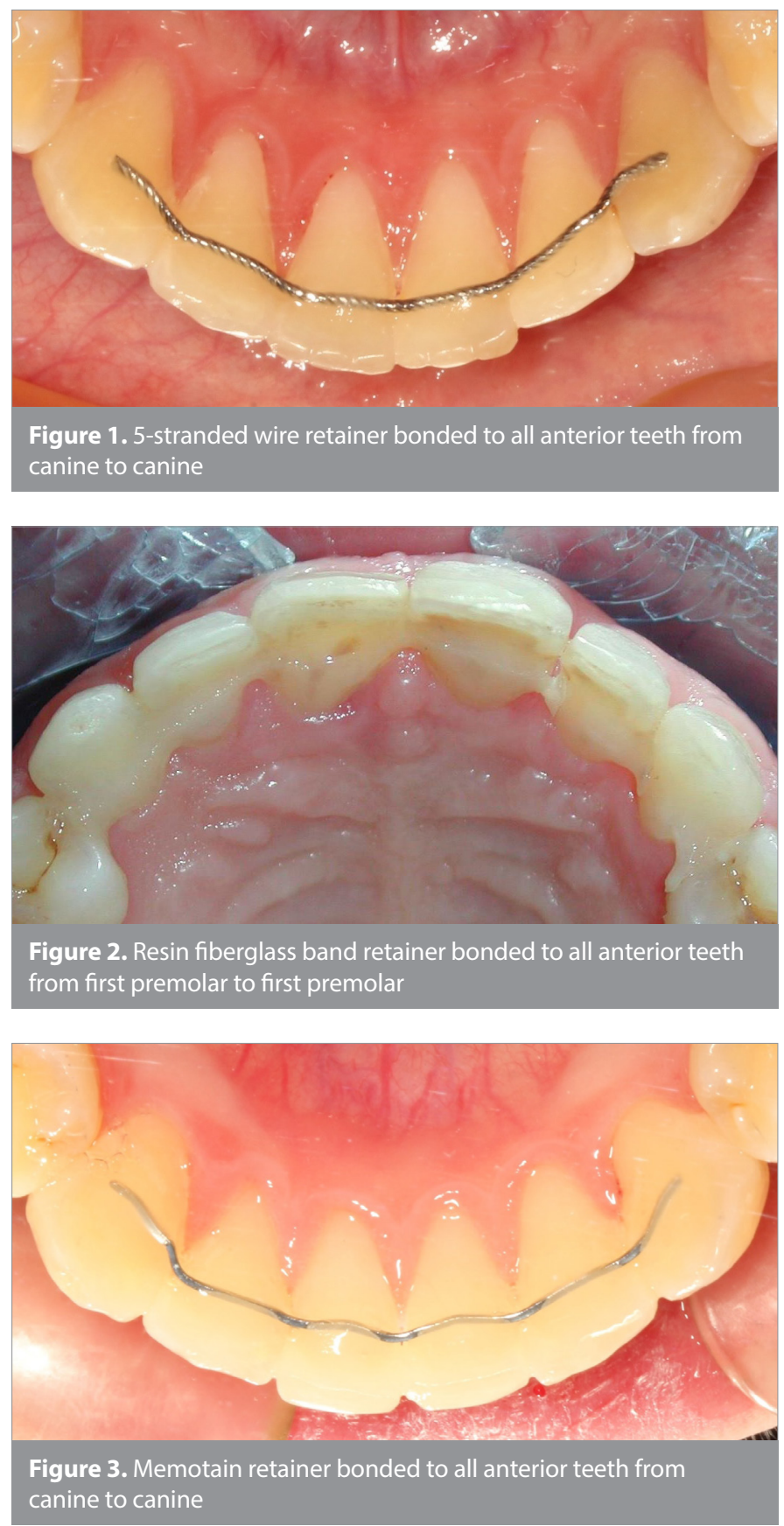
- $\quad$ cases with severe rotations and crowding in the lower incisors,

- cases in which lower inter-canine width is changed,

- cases treated with lower incisor proclination,

- cases with mild crowding that are treated without extractions,

- $\quad$ cases with deep overbite.

The indications for bonding fixed retainers to all teeth were defined by Zachrisson (28) as follows:

- cases in which median diastema is closed,

- cases with diastemas between the anterior teeth,

- $\quad$ adult patient with a potential for migration of the teeth after orthodontic treatment,

- $\quad$ cases with tooth loss or large diastemas in the maxilla before treatment,

- cases treated with mandibular incisor extraction,

- cases with severely rotated teeth before treatment,

- cases in which the position of a palatinally impacted canine is corrected.

The fixed retainers that are bonded to only canines are generally indicated when the anterior segment is moved toward the anteroposterior or lateral directions. If there is a risk of relapse for each tooth separately, then it will be wiser to bond the retainer to each tooth (1).

\section{Clinical Evaluation of Fixed Retainers}

Failure types, failure rates, and effects on periodontal health are the investigated issues in clinical studies related with bonded retainers.

\section{Failure Types of Fixed Retainers}

The reasons for failure of bonded fixed retainers include separation of tooth-adhesive interface, separation of wire-adhesive interface, breakage of retainer wire, and unwanted torque movements of the teeth caused by a retainer wire (29-33). It is reported that most of the failures are observed within the first 6 months of retainer use.

The most common failure type is separation of tooth-adhesive interface (29). The reported rate of this failure type in metal retainers is $3.5 \%-53 \%$, whereas this rate changes from $11 \%$ to $51 \%$ in fiber retainers (30-33). The reason for separation of tooth-adhesive interface is almost always related with extreme biting forces caused by eating hard foods. Therefore, patients wearing fixed retainers should abstain from biting hard foods directly. On the other hand, breakage of retainer wire is usually related with metal fatigue that is observed in long-term retainer use.

It is mentioned that the reason for separation of retainer wires from adhesive materials may result from either inadequate use of adhesive materials during the bonding stage or loss of adhesive material from composite surface due to abrasion in longterm use. Larger amounts of adhesive usage is recommended to increase the resistance to abrasion (1).
The less common failure types are opening of spaces between the teeth and sometimes displacement of the teeth or occurrence of dehiscence due to unexpected torque movements although there is no separation of retainer from tooth surface $(9,31,34-36) 2077$ female. Despite failure of fixed retainers is a multifactorial problem, disharmony between retainer wire and tooth surface, errors in wire placement or bonding technique and mechanical properties of retainer wires play an important role in failures (34). It is reported that passive adaptation of retainer wire to tooth surface, avoiding contamination of saliva during bonding, and abstaining from biting hard foods will increase the success rate of fixed retainers.

\section{Failure Rates of Fixed Retainers}

A number of studies investigating various types of retainer wires, adhesive materials, and bonding techniques used for fixed retainers can be found in the literature. There is a wide range for failure rates examined for each different type of fixed retainers. For stainless steel retainers, which are bonded to canines only, the failure rates are reported to be $13 \%-37.7 \%(27,37-39)$. On the other hand, the failure rates are reported to be $9 \%-14 \%$ when they are bonded to six lower incisors $(40,41)$.

The failure rates for multi-stranded retainers that became popular in recent years for their advantages are reported to be $8.8 \%-$ $46 \%(32,33,38,42,43)$. For resin fiberglass retainers, the failure rate was observed between $11 \%$ and $71 \%$, and the risk of failure for maxilla was reported to be higher than that for mandible for all examined fixed retainer types $(32,33,44)$.

\section{Effects of Fixed Retainers on Periodontal Health}

The biggest concern for bonded fixed retainers in long-term use is whether they make it more difficult to maintain oral hygiene and cause negative effects on periodontal health $(8,20,37,38$, 45-48). However, no consensus is found about this subject when the literature is reviewed. There are studies that show that bonded fixed retainers cause increased plaque and calculus accumulation or gingival inflammation. There are also other studies that show no negative effect.

Artun (20) compared the effects of different types of fixed retainer wires on caries formation and periodontal health and reported that although fixed retainers cause more plaque accumulation, they do not cause caries. Levin et al. (45) showed that bonded fixed retainers cause increased plaque accumulation, gingival recession, and bleeding on probing. Pandis et al. (8) reported that as a result of long-term tissue irritation, bonded fixed retainers cause an increase in pocket depth, marginal gingival recession, and calculus accumulation. However, these results were related with long-term wearing of fixed retainers rather than the materials used (20). It was remarked that the interproximal area beneath bonded fixed retainers was difficult to clean, thus more calculus was accumulated in this area $(8,46)$.

On the other hand, there are many studies that argue against these opinions. These studies revealed that even long-term wearing of fixed retainers caused no gingival tissue damage in most patients $(37,38,47,48)$. 
Rody et al. (47) placed fixed retainers in the mandibular anterior teeth and reported that although there is an increase in plaque accumulation, periodontal health is not affected. Booth et al. (37) reported acceptable gingival values in the mandibular anterior teeth after long-term wear of fixed retainers. Another study reported a decrease in bone level and remarked that it was due to orthodontic treatment rather than type of retention protocol (49).

\section{CONCLUSION}

Even though there are controversial studies in the literature, it is evident that bonded fixed retainers complicate maintaining oral hygiene. In light of this information, it is crucial to inform patients about the importance of brushing and flossing in details. They should also avoid biting hard foods, be motivated to protect their dental health, and be encouraged not to miss their periodic check-ups during the retention phase of orthodontic treatment (50).

Peer-review: Externally peer-reviewed.

Author Contributions: Concept - B.K.; Design - B.K.; Data Collection and/or Processing - Y.K.; Analysis and/or Interpretation - Y.K., B.K.; Literature Search - Y.K.; Writing Manuscript - Y.K., B.K.; Critical Review - Y.K., B.K.

Conflict of Interest: The authors have no conflict of interest to declare.

Financial Disclosure: The authors declared that this study has received no financial support.

\section{REFERENCES}

1. Bearn DR. Bonded orthodontic retainers: a review. Am J Orthod Dentofac Orthop 1995; 108: 207-13. [CrossRef]

2. Sonia M, Dosanjh K. Efficacy of Different Retention Types Post- Orthodontic Treatment. 2011;

3. Kingsley NW. A treatise on oral deformities as a branch of mechanical surgery. D. Appleton; 1880.

4. Lundström AF. Malocclusion of the teeth regarded as a problem in connection with the apical base. Am J Orthod Dentofac Orthop 1925; 11: 591-602. [CrossRef]

5. McCauley DR. The cuspid and its function in retention. Am J Orthod Oral Surg 1944; 30: 196-205. [CrossRef]

6. Tweed $\mathrm{CH}$. Indications for the extraction of teeth in orthodontic procedure. Am J Orthod Oral Surg 1944; 30: 405-28. [CrossRef]

7. Little RM, Riedel RA, Artun J. An evaluation of changes in mandibular anterior alignment from 10 to 20 years postretention. Am J Orthod Dentofac Orthop 1988; 93: 423-8. [CrossRef]

8. Pandis N, Vlahopoulos K, Madianos P, Eliades T. Long-term periodontal status of patients with mandibular lingual fixed retention. Eur J Orthod 2007; 29: 471-6. [CrossRef]

9. Renkema AM, Renkema A, Bronkhorst E, Katsaros C. Long-term effectiveness of canine-to-canine bonded flexible spiral wire lingual retainers. Am J Orthod Dentofac Orthop 2011; 139: 614-21. [CrossRef]

10. Renkema AM, Sips ET, Bronkhorst E, Kuijpers-Jagtman AM. A survey on orthodontic retention procedures in the Netherlands. Eur J Orthod 2009; 31: 432-7. [CrossRef]

11. Keim RG, Gottlieb EL, Nelson AH VD. JCO study of orthodontic diagnosis and treatment procedures. Part 1. Results and trends. J Clin Orthod 2002; 36: 553-68.

12. Pratt MC, Kluemper GT, Hartsfield Jr. JK, Fardo D, Nash DA. Evaluation of retention protocols among members of the American Asso- ciation of Orthodontists in the United States. Am J Orthod Dentofac Orthop 2011; 140: 520-6. [CrossRef]

13. Chinvipas N, Hasegawa Y, Terada K. Repeated bonding of fixed retainer increases the risk of enamel fracture. Odontology 2014; 102: 89-97. [CrossRef]

14. Newman G V. Epoxy adhesives for orthodontic attachments: progress report. Am J Orthod 1965; 51: 901-12. [CrossRef]

15. KNIERIM RW. Invisible lower cuspid to cuspid retainer. Angle Orthod 1973; 43: 218-9.

16. Degirmenci Z, Ozsoy OP. Retention after fixed orthodontic treatment. Cumhur Dent J 2009; 12: 83-90.

17. Årtun J. Caries and periodontal reactions associated with long-term use of different types of bonded lingual retainers. Am J Orthod 1984; 86: 112-8. [CrossRef]

18. Zachrisson BJ. Third-generation mandibular bonded lingual 3-3 retainer. J Clin Orthod 1995; 29: 39-48.

19. Zachrisson BU. Clinical experience with direct-bonded orthodontic retainers. Am J Orthod 1977; 71: 440-8. [CrossRef]

20. Årtun J, Zachrisson B. Improving the handling properties of a composite resin for direct bonding. Am J Orthod Dentofac Orthop 1982; 81: 269-76. [CrossRef]

21. Zachrisson BU. Multistranded wire bonded retainers: From start to success. Am J Orthod Dentofac Orthop 2015; 148: 724-7. [CrossRef]

22. Diamond M. Resin fiberglass bonded retainer. J Clin Orthod JCO 1987; 21: 182-3.

23. Orchin JD. Permanent lingual bonded retainer. J Clin Orthod JCO 1990; 24: 229.

24. Sachdeva RCL. SureSmile technology in a patient-centered orthodontic practice. J Clin Orthod 2001; 35: 245-53.

25. Kravitz ND, Grauer D, Schumacher P, Jo Y. Memotain: A CAD/CAM nickel-titanium lingual retainer. Am J Orthod Dentofac Orthop 2017; 151: 812-5. [CrossRef]

26. Liou EJW, Chen LIJ, Huang CS. Nickel-titanium mandibular bonded lingual 3-3 retainer: for permanent retention and solving relapse of mandibular anterior crowding. Am J Orthod Dentofac Orthop 2001; 119: 443-9. [CrossRef]

27. Lee RT. The lower incisor bonded retainer in clinical practice: a three year study. Br J Orthod. 1981; 8: 15-8. [CrossRef]

28. Zachrisson BU. The bonded lingual retainer and multiple spacing of anterior teeth. Swed Dent J Suppl 1982; 15: 247-55.

29. Iliadi A, Kloukos D, Gkantidis N, Katsaros C, Pandis N. Failure of fixed orthodontic retainers: A systematic review. J Dent 2015; 43: 876-96. [CrossRef]

30. Störmann I, Ehmer U. A prospective randomized study of different retainer types. J Orofac Orthop der Kieferorthopädie 2002; 63: 4250. [CrossRef]

31. Dahl EH, Zachrisson BU. Long-term experience with direct-bonded lingual retainers. J Clin Orthod JCO 1991; 25: 619-30.

32. Bolla E, Cozzani M, Doldo T, Fontana M. Failure evaluation after a 6-year retention period: a comparison between glass fiber-reinforced (GFR) and multistranded bonded retainers. Int Orthod 2012; 10: 16-28. [CrossRef]

33. Tacken MP, Cosyn J, De Wilde P, Aerts J, Govaerts E, Vannet BV. Glass fibre reinforced versus multistranded bonded orthodontic retainers: a 2 year prospective multi-centre study. Eur J Orthod 2010; 32: 117-23. [CrossRef]

34. Kučera J, Marek I. Unexpected complications associated with mandibular fixed retainers: A retrospective study. Am J Orthod Dentofac Orthop 2016; 149: 202-11. [CrossRef]

35. Brenchley ML. A cautionary tale of simplified retention. Br J Orthod 1997; 24: 113-5. [CrossRef]

36. Katsaros C, Livas C, Renkema AM. Unexpected complications of bonded mandibular lingual retainers. Am J Orthod Dentofac Orthop 2007; 132: 838-41. [CrossRef] 
37. Booth FA, Edelman JM, Proffit WR. Twenty-year follow-up of patients with permanently bonded mandibular canine-to-canine retainers. Am J Orthod Dentofac Orthop 2008; 133: 70-6. [CrossRef]

38. Al-Nimri K, Al Habashneh R, Obeidat M. Gingival health and relapse tendency: a prospective study of two types of lower fixed retainers. Aust Orthod J 2009; 25: 142.

39. Årtun J, Spadafora AT, Shapiro PA. A 3-year follow-up study of various types of orthodontic canine-to-canine retainers. Eur J Orthod 1997; 19: 501-9. [CrossRef]

40. Cerny R. The reliability of bonded lingual retainers. Aust Orthod J 2007; 23: 24.

41. Lee KD, Mills CM. Bond failure rates for V-loop vs straight wire lingual retainers. Am J Orthod Dentofacial Orthop 2009; 135: 502-6. [CrossRef]

42. Pandis N, Fleming PS, Kloukos D, Polychronopoulou A, Katsaros C, Eliades T. Survival of bonded lingual retainers with chemical or photo polymerization over a 2-year period: a single-center, randomized controlled clinical trial. Am J Orthod Dentofacial Orthop 2013; 144: 169-75. [CrossRef]

43. Lie Sam Foek DJ, Ozcan M, Verkerke GJ, Sandham A, Dijkstra PU. Survival of flexible, braided, bonded stainless steel lingual retainers: a historic cohort study. Eur J Orthod 2008; 30: 199-204. [CrossRef]
44. Ardeshna AP. Clinical evaluation of fiber-reinforced-plastic bonded orthodontic retainers. Am J Orthod Dentofac Orthop 2011; 139: 761-7. [CrossRef]

45. Levin L, Samorodnitzky-Naveh GR, Machtei EE. The association of orthodontic treatment and fixed retainers with gingival health. J Periodontol 2008; 79: 2087-92. [CrossRef]

46. Butler J, Dowling P. Orthodontic bonded retainers. J Ir Dent Assoc 2005; 51: 29-32.

47. Rody Jr WJ, Akhlaghi H, Akyalcin S, Wiltshire WA, Wijegunasinghe $M$, Filho GN. Impact of orthodontic retainers on periodontal health status assessed by biomarkers in gingival crevicular fluid. Angle Orthod 2011; 81: 1083-9. [CrossRef]

48. Heier EE, De Smit A, Wijgaerts IA, Adriaens PA. Periodontal implications of bonded versus removable retainers. Am J Orthod Dentofac Orthop 1997; 112: 607-16. [CrossRef]

49. Westerlund A, Oikimoui C, Ransjö M, Ekestubbe A, Bresin A, Lund $\mathrm{H}$. Cone-beam computed tomographic evaluation of the long-term effects of orthodontic retainers on marginal bone levels. Am J Orthod Dentofac Orthop 2017; 151: 74-81. [CrossRef]

50. Corbett Al, Leggitt VL, Angelov N, Olson G, Caruso JM. Periodontal health of anterior teeth with two types of fixed retainers. Angle Orthod 2015; 85: 699-705. [CrossRef] 